\title{
La Segunda Celestina de Feliciano de Silva a la luz de nuevos datos sobre su biografía
}

\author{
Jesús Fernando Cáseda Teresa \\ I.E.S. Valle del Cidacos Calahorra (La Rioja)
}

\section{RESUMEN}

Este estudio aporta un buen número de documentos desconocidos que dan luz sobre la biografía de Feliciano de Silva, localizados en el Archivo Histórico de la Nobleza. Da noticia de su fecha de nacimiento (1479), asunto que tanto debate ha suscitado a lo largo de los años, y desvela muchos aspectos relativos a su familia, a su situación económica, etc. Establece el origen de diversos personajes de su continuación de La Celestina a partir de su biografía: su primo el «arcediano» o el "arcediano el viejo», Polandria — su esposa Gracia Fe-, Celestina —probablemente Catalina Maldonado-, etc. Estudia algunas curiosas relaciones onomásticas de la obra con los nombres que aparecen en otras obras de sus amigos judeoconversos portugueses o de Núñez de Reinoso. Y sitúa el origen de otros muchos personajes de su comedia: por ejemplo el juego onomástico con su propio nombre en el caso de Félides o Filínides, que ocultan en ambos casos a Feliciano de Silva.

Palabras Clave: Segunda Celestina; Feliciano de Silva; biografía; onomástica; siglo XVI.

\section{Feliciano de Silva's Segunda Celestina in the light of new biographical data}

\section{ABSTRACT}

This study provides a good number of unknown documents that shed light on the biography of Feliciano de Silva, kept in the Historical Archive of the Nobility. It provides information on his date of birth (1479), a question that has provoked much discussions over the years, and reveals many details related to his family life, his financial situation, etc. It determines the origins of various characters of his continuation of La Celestina on account of his biography: his cousin the "archdeacon» or the «archdeacon the old», Polandria — his wife Gracia Fe-, Celestina - probably Catalina Maldonado-, etc. It studies some curious onomastic relationships of the work with the names that appear in other works of his friends, Portuguese Judeo-converts or Núñez de Reinoso. And it locates the origin of many other characters of his comedy: for example, the play-on-name with his own name in the case of Felides or Filinides, who in both cases conceal the name of Feliciano de Silva.

KeYwords: Segunda Celestina; Feliciano de Silva; biography; naming; 16th century. 


\section{1.- Feliciano de Silva: Una biografía incompleta}

Pese a que Feliciano de Silva fue uno de nuestros más importantes escritores del siglo XVI, su biografía es, sin embargo, en gran medida desconocida. Algunos veteranos trabajos como el llevado a cabo por Narciso Alonso Cortés (1933) y antes por Emilio Cotarelo y Mori (1926) y Erasmo Buceta (1931) sirvieron para redescubrirnos a uno de los más exitosos prosistas de los Siglos de Oro, algo en lo que ya insistió Menéndez Pelayo en sus Orígenes de la novela, reivindicándolo y ajustando, y también minimizando, la conocida crítica de Cervantes en el Quijote dirigida contra su obra.

Diversos estudios de Rosa María Lida de Malkiel (1961) sobre su Segunda Celestina, de S.P. Cravens (1976) sobre Feliciano de Silva y los antecedentes de la novela pastoril, o de Daniel Eisenberg (2000) sobre sus novelas de caballerías sirvieron para acrecentar y remarcar su importancia como novelista e iniciador de diversos géneros; pero apenas repararon en la cuestión biográfica del escritor de Ciudad Rodrigo, asunto fundamental para la mejor compresión de su obra por muchas cuestiones que luego señalo.

Luis Fernández nos enseñó en su trabajo "Feliciano de Silva y el movimiento comunero en Ciudad Rodrigo» (1977) que el autor de la Segunda Celestina fue fiel a la causa de Carlos V, cuestión de cierta relevancia; y la profesora de la Universidad de Zaragoza María Carmen Marín Pina en su estudio "Nuevos datos sobre Francisco Vázquez y Feliciano de Silva, autores de libros de caballerías» (1991) supo ver la íntima relación entre la biografía del escritor y su labor como novelista.

Pero con la excepción de estos últimos, apenas se ha reparado en esta cuestión que considero esencial para la comprensión de su obra y para explicar el origen de sus creaciones.

Cierto es que se ha subrayado la importante relación de Silva con otros escritores contemporáneos, como los portugueses Jorge de Montemayor, Bernardim de Ribeiro y Sá de Miranda, o con el castellano Núñez de Reinoso. Los cinco formaron una suerte de círculo literario con multitud de contactos epistolares y literarios, circuito de mutua influencia que ha sido estudiado por Cravens (1976) y por otros investigadores como Consolación Baranda (1984), Asunción Rallo (1995) y Teijeiro Fuentes (2007). Tal relación pudo comenzar sobre 1530. Hubbard Rose (1971), por su parte, indicó en un veterano estudio que Feliciano de Silva introdujo en el círculo de escritores portugueses al castellano Núñez de Reinoso.

Según Gema Montero García,

La posible influencia de Ribeiro, autor de Menina e moça (1554), obra donde se entremezclan elementos pastoriles, caballerescos y sentimentales82, pudo servir de inspiración para la incursión del elemento pastoril en los libros de Silva, sobre todo a partir del Amadís de Grecia 
(Cravens, 1976: 27). Otro amigo portugués de Silva y de Núñez de Reinoso, fue Jorge de Montemayor, autor de la primera novela pastoril española Los siete libros de la Diana (1559), donde se observa el intrusionismo del elemento caballeresco en lo pastoril. (Montero, 2016: 61)

Se ha aludido repetidamente - monotema biográfico del autor-a su conocido "Sueño de Feliciano de Silva» inserto en su Amadís de Grecia, donde se refiere a su matrimonio con la hija del judeoconverso y exiliado en Portugal Hernando de Caracena, Gracia Fe, aunque el propio Feliciano de Silva difundió ciertos rumores de que era hija ilegítima del duque del Infantado.

El trabajo que ahora inicio tiene como objetivo principal analizar la Segunda Celestina de Feliciano de Silva a partir de diversos descubrimientos biográficos que tienen algún interés, según mi punto de vista, para entender mejor su obra y para establecer, en algunos casos, la relación de muchos de sus personajes con el juego onomástico, muy del gusto de nuestro escritor y también de Reinoso, de Montemayor o incluso de Sá de Miranda y del también portugués Bernardim de Ribeiro. Todos ellos, siguiendo a Sannazaro, pero también a la novela de caballerías, llenaron sus obras de multitud de referencias biográficas propias o de amigos y familiares, moda que persistirá en la novela pastoril, en la sentimental y también, hasta en sus últimos ejemplos, en las novelas de caballerías.

En cualquier caso, considero importante acercarnos a la biografía de Feliciano de Silva para entender mejor su obra, especialmente su Segunda Celestina, llena de guiños a su propia vida, a su familia y a sus amigos.

No es, sin embargo, difícil localizar datos de Feliciano de Silva en los archivos de Ciudad Rodrigo, donde vivió la mayor parte de su vida. Según el historiador local Mateo Hernández Vegas, llevó una vida muy intensa, ocupado en múltiples quehaceres:

En el Ayuntamiento, como regidor; en los tribunales, como árbitro (oficio para el cual debía tener condiciones excepcionales); en los testamentos y particiones, como perito; en las posesiones de canonjías, como testigo; ¿qué más, si hasta se da el caso de que, siendo lego, el Cabildo le nombra representante suyo en el Concilio de Salamanca? (Hernández Vegas, 1982: 104)

Numerosos estudios han analizado en la continuación de la Celestina por el escritor castellano, entre otros Whinnom con su trabajo «El género celestinesco: origen y desarrollo» (1988); Consolación Baranda, quien le dedicó su Tesis Doctoral y es autora de una edición (1988). Emilio José Sales Dasí ha estudiado el humor en su obra (2005). Joseph T. Snow (2018) ha incardinado el texto de Silva en la tradición celestinesca de su 
época, en prosa o en verso. Pierre Heugas (1973), mucho antes, analizó la relación con la primitiva obra de Rojas y Proaza.

No podemos olvidar, a este respecto, la edición de José María Valverde con Manuel Criado de Val en las lejanas fechas de 1976. O los estudios de Javier Martín Lalanda (2002) y el trabajo reciente de José Luis Gonzalo Sánchez-Molero (2018) sobre la recepción de Feliciano de Silva a través del estudio de las bibliotecas e inventarios de lectores de la época. Y, antes, las interesantes apreciaciones del también dramaturgo y paisano, Fernando Arrabal (1987), en la reivindicación de su figura.

\section{2.- Aportaciones biográficas a partir del análisis de los documentos del Archivo Histórico de la Nobleza}

Feliciano de Silva, nacido en el último tercio del siglo xv, perteneció a la familia de los Silva, de origen portugués, cuyo padre, Tristán de Silva, fue cronista de Carlos V. Asentada la familia en la fronteriza con Portugal localidad de Ciudad Rodrigo, actual provincia de Salamanca, Tristán de Silva participó en la guerra de Granada y fue regidor de esta entre 1491 y 1492, además de alcalde de Madrid.

Sabemos que Feliciano, siendo muy joven, sirvió al arzobispo de Sevilla, Diego de Deza, al que dedicó su Lisuarte de Grecia, texto publicado en las prensas de la ciudad andaluza. Parece que participó en la guerra de las Comunidades (1520-1521) del lado del emperador, durante los dos años en que estuvo a su servicio. Más tarde fue regidor, como su padre, de Ciudad Rodrigo, con carácter vitalicio y tras contender judicialmente contra un férreo opositor que le acusó, con evidente mala fe, de comunero. Antes parece que estuvo en América, aunque esto último no se ha estudiado con el detalle que probablemente merece. En 1520, se casó con la citada Gracia Fe, hija del judeoconverso Hernán de Caracena, pese a la oposición de su familia. Su «Sueño» viene a reivindicarla haciéndola presunta hija, aunque ilegítima, del duque de Infantado, Íñigo López de Mendoza (1438-1500).

Sobre su viaje americano, señala Gema Montero García en su Tesis Doctoral sobre el Florisel de Niquea que debió de embarcar

en la expedición de Pedrarias Dávila hacia el Darién, en el istmo de Panamá, junto a Bernal Díaz del Castillo y Gonzalo Fernández de Oviedo. Al parecer, regresó a España en 1515, pero antes había gestionado con su hermano, el canónigo Juan de Silva, continuo de fray Diego de Deza, la publicación de su Lisuarte de Grecia en 1514. Poco se sabe de la vida de Feliciano entre los años de 1515 y 1530 (año de publicación de la primera edición 
de Amadís de Grecia). Se cree que durante estos años pudo prestar dos años de servicios al emperador Carlos V, según aparece en su testamento de 1554: "Yten mando que cobren de su magestad dos años de mi servicio que me deve». (Montero, 2016: 54)

Respecto a la guerra de las Comunidades, Ciudad Rodrigo se declaró en 1521 favorable al emperador, así como también el entonces regidor Feliciano de Silva. Según Luis Fernández (1977), una provisión real le otorgó de por vida el puesto de regidor en su localidad. Para Cravens, sus elogios al frente de la Cuarta Parte del Florisel de Niquea a la infanta María, hija del emperador, y las no menores alabanzas de los éxitos militares de su padre son razones bastantes para apostar por su postura anticomunera. Señala Gema Montero García en su Tesis Doctoral sobre la última novela citada, el Florisel de Niquea, que

Es importante señalar que, respecto al supuesto «inmovilismo» de nuestro autor, si viajó al Nuevo Mundo, tuvo que recorrer la región castellana donde vivía. Que, posiblemente, asistiera a las bodas de Felipe II en Salamanca, celebradas en 1543, y a las bodas de la infanta María con Maximiliano de Hungría, celebradas en Valladolid en 1548, ciudades próximas a Ciudad Rodrigo (Cravens, 1976: 75). Además, también es de suponer, que visitaría en alguna ocasión a los impresores de sus obras, lo que le llevaría por toda Castilla y hasta Sevilla. Sin lugar a dudas "un espíritu inquieto y aventurero». (Montero, 2016: 55)

No es mucho más lo que conocemos de este importante escritor. Sin embargo, diversos documentos que he localizado en el Archivo Histórico de la Nobleza pueden servirnos para completar algunas partes de su biografía hasta ahora desconocidas y de los que ahora procedo a dar cuenta.

Sabemos, a través de un documento de fecha de 11 de julio de 1503, que su madre, Mayor de Guzmán, ya era viuda aquel año, siendo nombrada entonces «curadora de la persona y bienes de sus hijos, Isabel, María y Feliciano de Silva por el fallecimiento» de su marido Tristán de Sil$\mathrm{va}^{1}$. Por tanto todavía entonces - 1503- Feliciano era menor de edad por ser su madre su "curadora».

Un año más tarde, el 5 de febrero de 1504, se firmó una «Escritura de traspaso y cesión del censo que Mayor de Guzmán, viuda de Tristán de Silva, tenia contraído con Alonso de Silva por juro de heredad, a favor de Feliciano de Silva» ${ }^{2}$. 
Y de solo un mes después — 15 de marzo de 1504- es otra «Escritura de cesión y donación otorgada por Juan de Silva y Pedro de Silva a favor de su sobrino, Feliciano de Silva, hijo de Tristán de Silva, de un juro de heredad para siempre $»^{3}$.

Parece, por tanto, que entre 1503 y 1504, y tras el reciente fallecimiento de su padre, Tristán de Silva, Feliciano tuvo que hacerse cargo de la casa de los Silva en la localidad de Ciudad Rodrigo, el cual tenía, como señala el primer documento señalado, dos hermanas, Isabel y María y, como luego veremos, dos hermanos varones, Juan y Tristán de Silva, además de otra hermana no señalada en el anterior documento, de nombre Aldonza. Aunque, sin embargo, como señala Mateo Hernández Vegas:

Feliciano de Silva tuvo tres hermanos: Tristán de Silva, el mayor, que de muy joven pasó a las Indias, y había muerto en 1511, fecha de la escritura citada, por lo cual no se menciona en ella; seguía en edad Feliciano, después Juan, que, como hemos visto en otro lugar, fué canónigo de Ciudad Rodrigo, por renunciar en él la prebenda su tío don Juan de Silva, mediando con el Cabildo Feliciano; y María de Guzmán, que equivocadamente llaman algunos Aldonza, la cual casó con su sobrino Hernán Nieto de Silva. (Hernández Vegas, 1982: 105)

Parece que su minoría de edad le impidió en 1503 hacerse cargo de los bienes familiares y su madre $\mathrm{D}^{a}$ Mayor por tal razón actuó como curadora de su hijo. Según Máximo García Fernández, en la Castilla rural de la época,

Inmersos en una confluencia de intereses comunitarios afines, la necesidad de defender la supervivencia y los patrimonios de los menores se fue incrementando en la Castilla interior durante el Antiguo Régimen; también, y fundamentalmente, en los espacios rurales campesinos. Entonces, la participación familiar muy próxima aumentó, en muchas ocasiones las mismas madres, tratando de proteger el mundo juvenil hasta su mayoría de edad. (García Fernández, 2016: 52)

Entonces, siguiendo lo dispuesto por las Partidas de Alfonso X el Sabio, la mayoría de edad no se adquiría hasta los veinticinco años, lo cual permite deducir que si en 1504 Feliciano de Silva recibe en su propio nombre los censos de sus familiares, uno cedido por su madre en nombre de Alonso de Silva, probablemente cuñado de esta última, y hermano de su difunto esposo Tristán de Silva, y otro directamente de sus también 
tíos Juan de Silva y Pedro de Silva, en el mismo año, ello es debido a que justo entonces cumplió Feliciano los veinticinco años, pues solo un año antes, en 1503, no pudo actuar en su propio nombre sino a través de su madre. Si en 1504 contaba con veinticinco, habría nacido en 1479. Sabemos que murió el 24 de junio de 1554, cuando por tanto contaba con setenta y cinco de edad. Su Lisuarte de Grecia, publicado en Sevilla en 1514, apareció cuando tenía treinta y cinco años. Y su Segunda Celestina, de 1534, publicada veinte más tarde que la anterior, fue dada a la luz a la edad de cincuenta y cinco.

Emilio Cotarelo (1926) consideró, equivocadamente, que Feliciano de Silva nació alrededor de 1492, puesto que su hermano, según él, nació un año más tarde, en 1493, basándose para ello en el testimonio del sobrino del escritor, Manuel de Silva, en un proceso de limpieza de sangre del nieto de Feliciano, Fernando de Toledo, que aportó para su ingreso en la orden de Santiago.

Narciso Alonso Cortés (1933) propuso por su parte la fecha de 1480, aunque no dio razón para fundamentar dicha conclusión. Y Cravens (1976) apostó por su nacimiento, como Cotarelo, en 1492, basándose fundamentalmente en la fecha de nacimiento de una hermana suya, la citada Aldonza de Silva, en aquel año, la menor de todos. Para María Carmen Marín Pina (1991), su nacimiento estaría situado entre 1480 y 1490. Su hermano Tristán, trasladado a América, ya no vivía en 1496, fecha del testamento del padre de todos ellos.

El seis de mayo de 1505, la madre de Feliciano otorga testamento, como «mujer de Tristán de Silva, en el que nombra por herederos a sus hijos Feliciano, Aldonza, Isabel, Juan y Tristán de Silva, y a María de Guzmán»"

Luis de Salazar y Castro (1685) en su Historia genealógica de la casa de Silva refiere que los padres de Feliciano se casaron en Segovia, de donde era doña Mayor de Guzmán, el 12 de octubre de 1477. Resulta por tanto factible que Feliciano, si acaso no fue el mayor, sí que tuvo que hacerse cargo del destino patrimonial de la familia toda vez que su hermano Tristán pasó la mayor parte de su vida en América. Luis de Salazar cita a este último en primer lugar, dando a entender que era de edad superior a la de Feliciano. Del otro hermano, Juan de Silva, señala que «no tenemos noticia» quizás porque falleció tempranamente.

Tampoco la Historia genealógica de la casa de Silva da noticia de las hermanas Isabel y María aunque sí de Aldonza, de la cual señala que "casó con su sobrino Fernán Nieto de Silva, señor de Bañabares, padres de Diego de Guzmán de Silva, canónigo de Toledo, embajador en Inglaterra y Venecia y últimamente cardenal de la Santa Iglesia de Roma».

La madre de Feliciano, Mayor de Guzmán, era hija de Gonzalo Mexía de Virués, regidor de Segovia, y de doña María de Guzmán, nieta de Fer- 
nán Sánchez de Virués y de Mayor de Pedrola, descendiente esta última de doña María de Guzmán, la hija de Gonzalo Pérez de Guzmán y de Violante de Quiñones, según el mismo Luis de Salazar y Castro.

A lo largo de su vida, Feliciano tuvo una buena relación con el duque de Béjar, a quien dedicó su Segunda Celestina y el Florisel de Niquea en su tercera parte. Probablemente, se trataba de un familiar lejano, pariente por parte de su madre, Mayor de Guzmán, y de su bisabuelo Gonzalo Pérez de Guzmán. No deja de ser curioso que también Cervantes dedique su Quijote al duque de Béjar, en este caso el bisnieto de Álvaro de Zúñiga y Pérez de Guzmán a quien se refiere en sus obras Feliciano de Silva.

Su hijo del mismo nombre, Feliciano de Silva, evitó con su arrojo que en 1540 muriera ahogada en Sevilla la duquesa doña Ana de Aragón, esposa del sexto duque de Medina Sidonia, Juan Alonso de Guzmán «el Bueno", a quien entonces el joven descendiente del escritor de Ciudad Rodrigo servía como paje.

De manera que, como sabemos, Feliciano mantuvo a lo largo de toda su vida una buena relación con dos de las familias más distinguidas del reino, los Medina Sidonia y los duques de Béjar. En ningún caso percibimos rastro alguno de sangre judía en sus orígenes. Y, sin embargo, sus relaciones literarias y de amistad con Montemayor, con Bernardim de Ribeiro, judeoconversos portugueses, o con Alonso Núñez de Reinoso, también judeoconverso, así como su matrimonio con la hija del judío Hernán de Caracena, Gracia Fe, nos llevan a la órbita del mundo de los judeoconversos, los más activos creadores de literatura tanto poética como en prosa y también lectores de literatura caballeresca desde la época de Pedro López de Ayala, como ha señalado Alla Markova (2009), quien descubrió una novela de caballerías incompleta, "escrita o adaptada para judíos».

En el Archivo de la Nobleza, abundan las noticias sobre Feliciano de Silva. Por ejemplo, en 1510, una «Escritura de compraventa otorgada por Feliciano de Silva, a favor de Aldonza Enríquez, esposa de Diego de Herrera, de una renta sobre los bienes de Pedro de Silva, regidor de Ciudad Rodrigo (Salamanca)»" ${ }^{5}$ del mismo año - 1510 — son unas "Escrituras de compraventa entre Feliciano de Silva, y Gaspar Sánchez, cura de Zamarra (Salamanca), de unos casares, solares y casas en la calle de la Rúa Vieja de dicha villa " $; y$ también, de igual fecha, una "Escritura de compraventa otorgada por Feliciano de Silva, a favor de Juana de Silva, de unas casas en la calle Rúa Vieja, de Zamarra» ${ }^{7}$.

Parece que de esta última, su familiar — prima - Juana de Silva, fue acreedora de algunas deudas que generaron el embargo de varios de sus bienes. Esta es la causa, en 1517, de una "Escritura de empeño otorgada

\footnotetext{
5.- Archivo Histórico de la Nobleza. ES.45168.AHNOB//YELTES,C.7,D.95-98.

6.- Archivo Histórico de la Nobleza. ES.45168.AHNOB//YELTES,C.7,D.95-98.

7.- Archivo Histórico de la Nobleza. ES.45168.AHNOB//YELTES,C.7,D.95-98.
} 
por Feliciano de Silva, a favor de Juana de Silva, hija de Pedro de Silva, de unas casas en la «rúa vieja» de Ciudad Rodrigo (Salamanca) por el impago de una deuda por parte del primero».

Se llegó a decir que Feliciano de Silva acumuló un buen capital gracias a la venta de sus obras, reeditadas en multitud de ocasiones en vida del autor. Sin embargo, Jorge de Montemayor ya advirtió que acumuló "más honra que dineros». Y la anterior "escritura de empeño" promovida por su familiar Juana de Silva parece, ya en 1517, darle la razón al escritor portugués.

De nuevo esta, Juana de Silva, en 1524, logró, a causa de las deudas de su familiar, el otorgamiento de una "Escritura de compraventa otorgada por Feliciano de Silva, regidor de Ciudad Rodrigo (Salamanca), a favor de su prima Juana de Silva, hija de Pedro de Silva, de una casa en la calle Rúa Vieja, en dicha ciudad ${ }^{9}$. Con ella se cobraba las diferencias, a precio ventajoso, del préstamo hipotecario hecho a su primo el autor del Lisuarte de Grecia.

A este respecto, el Archivo Histórico de la Nobleza guarda un abundante número de relaciones judiciales entre un familiar de Feliciano, el arcediano Juan Gómez de Silva, y este.

En 1507, se firmó una «Escritura de trueque y cambio entre Juan Gómez de Silva, arcediano de Sabugal (sic), y Feliciano de Silva, hijo de Tristán de Silva, de unas casas propiedad de éste en Ciudad Rodrigo (Salamanca), por una renta de hierba en Villar del Rey (Badajoz), propiedad del primero» ${ }^{10}$.

En 1512, de nuevo ambos volvieron a firmar unas «Escrituras de apartamiento y constitución de nueva hipoteca entre Juan de Silva, arcediano en la catedral de Ciudad Rodrigo (Salamanca) y Feliciano de Silva, regidor de dicha ciudad, sobre una renta de hierba en la dehesa de Villar del Rey, por unas casas en Salamanca propiedad del último» ${ }^{11}$. La causa de este último negocio jurídico parece clara: la situación de déficit económico o impago de Feliciano de Silva que, como luego ocurrirá con el anteriormente asunto de Juana de Silva, muestra sus penurias económicas.

El mismo arcediano, Juan de Silva, se hace cargo de los bienes de su hermano Pedro de Silva, según negocio firmado en 1509 que aparece en una "Información dada a instancia de Diego de Silva, por la compra a Juan de Silva, arcediano de ciertas rentas por el valor de ocho mil maravedíes para favorecer a su a su hermano Pedro de Silva del que es su curador $\aleph^{12}$.

\footnotetext{
8.- Archivo Histórico de la Nobleza. ES.45168.AHNOB//YELTES,C.9,D.36.

9.- Archivo Histórico de la Nobleza. ES.45168.AHNOB//YELTES,C.7,D.110

10.- Archivo Histórico de la Nobleza. ES.45168.AHNOB//YELTES,C.7,D.100.

11.- Archivo Histórico de la Nobleza. ES.45168.AHNOB//YELTES,C.9,D.34-35.

12.- Archivo Histórico de la Nobleza. ES.45168.AHNOB//YELTES,C.3,D.44.
} 
Sabemos que este arcediano y familiar de Feliciano, Juan de Silva, fue hijo de su homónimo Juan de Silva y de la esposa de este, de nombre Teresa, hermano de Diego de Silva, regidor, como Feliciano, de Ciudad Rodrigo, según un «Testimonio notarial dado por Pedro de Escobar, de las cuentas y partición de los bienes de Juan de Silva y de su esposa Teresa, adjudicados a sus hijos Juan de Silva, arcediano, y Diego de Silva, regidor de Ciudad Rodrigo (Salamanca)» de 1508 que se conserva en el Archivo Histórico de la Nobleza ${ }^{13}$.

Este arcediano de Portugal y también de Ciudad Rodrigo debía de tener buena disposición para los negocios, pues conservamos una "Carta de poder otorgada por Diego de Silva a favor del arcediano Juan de Silva para hacer compraventa de las alcabalas del vino, carne y heredades de Ciudad Rodrigo (Salamanca) que son de su propiedad» ${ }^{14}$ de 1517.

Las dificultades económicas de Feliciano de Silva no solo le persiguieron a él, sino también a su esposa Gracia Fe, incluso antes del fallecimiento de este. En 1547 se firmó una «Escritura de traspaso de censo de una hipoteca otorgada por Gracia, mujer de Feliciano de Silva a favor de Catalina de Carvajal», según se desprende a su vez de una "Escritura de hipoteca otorgada por Juana Hernández, viuda de Pedro de Grado, a favor de Gracia, mujer de Feliciano de Silva» ${ }^{15}$.

Y la situación de esta, ya viuda, pudo empeorar con el fallecimiento del escritor de Ciudad Rodrigo. En 1564, diez años después de la muerte de Feliciano -1554-, su esposa Gracia Fe firmó una «Escritura de hipoteca otorgada por Isabel de Aldana, viuda de Juan Hernández, a favor de Gracia, mujer de Feliciano de Silva, cuyo aval es impuesto sobre una casa y bodega en el término de Ciudad Rodrigo (Salamanca)» ${ }^{16}$. Un año más tarde, en 1565, fue objeto de un pleito de su familiar Hernando Silva, según una «Ejecutoria del pleito litigado por Hernando Silva, vecino de Ciudad Rodrigo (Salamanca), con Gracia, viuda de Feliciano de Silva, vecina de Ciudad Rodrigo (Salamanca), Diego de Silva, su hijo, vecino de Cuzco (Perú) y Aldonza Herrero, vecina de Salamanca, sobre ocupación y restitución de unas casas recibidas por herencia de Tristán de Silva» ${ }^{17}$.

Según Narciso Alonso Cortés, estudió Feliciano en Salamanca, algo que en efecto parece verificarse a través de la lectura del testamento de su padre, Tristán. En este se dice así, en fecha de 1496:

[...] y si el dicho Juan de silua ansi mesmo fallesciere sin tener hijo barón heredero, los aya tristan de silua, e asi

\footnotetext{
13.- Archivo Histórico de la Nobleza. ES.45168.AHNOB//YELTES,C.9,D.3.

14.- Archivo Histórico de la Nobleza. ES.45168.AHNOB//YELTES,C.26,D.36.

15.- Archivo Histórico de la Nobleza. ES.45168.AHNOB//YELTES,C.8,D.65-66.

16.- Archivo Histórico de la Nobleza. ES.45168.AHNOB//YELTES,C.8,D.6.

17.- Archivo Histórico de la Nobleza. ES.47186.ARCHV//EJECUTORIAS,CAJA 1087,26.
} 
después mi hijo Juan de guzman, con tal que si alguno de los tres mis hijos primeros fuere de la yglessia, aya el mayor en la dicha manera de los que fuesen legos, otrosí esto ansi cumplido e acauado, costituyo e ago mis vniverssales herederos a los dichos mis hijos feliciano y doña aldonca de silua e Jhuan de silua de guzman e tristan de silba e juan de guzman e doña maria de guzman para que cunplido e acauado lo sussodicho partan ygualmente lo rrestante, otro si mando que asta que cada vno de mis hijos e hijas aya veinte e cinco años, aya la dicha mi muger doña mayor de guzman su madre todos e qualesquier mis bienes raizes e que sea su tutora e curadora, e que si la dicha mi muger fallesciere, lo que quiera nuestro sseñor que asi no ssea, con quanta rreberencia puedo e debo muy humilmente suplico e por servicio de nuestro sseñor pido a la muy excelente rreina nuestra sseñora, que por lo que debe a su gran alteca e nobleca rreal quiera que su magestad auer la cura dellos o mandarles pagar en juro o como mas seruida fuere cantidad de dos quentos y medio que su alteca verdaderamente me es en cargo de diez y seis años que la serbi sin que su alteca me diese o mandase dar valía de vn maravedí, y esto se entiende con lo que mi padre me quitó de su hacienda porque contra su boluntad serui e segui al rrey nuestro señor y a su alteca sin los quales dos quentos e medio me es en cargo agora su alteca de años de mi rracion e quitación e ayuda de costa, e si su alteca no fuere seruido de lo acetar, mando que lo ssea mi hermano hernando de silua e que por ello aya seys myll maravedís cada vn año y lo otro que mi hacienda rrentase se gaste con mis hijos para que aprendan en Salamanca é con mis hijas en vn monesterio con que sea el de carcosso o el de cotia con la sseñora abadessa doña guiomar mientras se casen o metan en religión o como estén bien, otro si mando qne luego como yo fallesciere baya mi muy amada muger a do quiera que la rreyna nuestra sseñora estubiere y le suplique por la gratificación de treinta años que la he seruido y la paga de lo susso dicho e ansí al rrey nuestro señor, e dé a sus alteras esta carta que dentro en este testamento está, e otra que tanvien en él está a los sseñores arcovispo de toledo e de granada, o a qualquiera dellos que en la corte estoviere y les suplique quieran ser yntercessores para con sus altecas... fize esta carta de mi 
mano en presencia del scriuano e testigos yuso scriptos. (Alonso Cortés, 1933: 28)

Tuvo siete hijos de nombres Diego de Silva, Luis de Silva, Feliciano de Silva, María de Silva, Aldonza de Silva, Isabel de Silva y Mayor de Guzman.

Según Mateo Hernández Vegas,

Pocas noticias tenemos de la mujer de Feliciano, lo cual no es de extrañar, pues se sospecha que era de abolengo judío. Sólo dos veces hemos visto su nombre, las dos en documentos del Hospital de la Pasión: En el acta de 3 de Mayo de 1561, son admitidas cofradas «las señoras Gracia, mujer que fué del señor Feliciano de Silva, difunto, y doña Aldonza de Silva, su hija.»Y en el legajo III, número 62, se halla una "carta de pago otorgada por doña María de Silva (hija, como veremos, de Feliciano) mujer de don Fadrique de Toledo, clavero de Alcántara, difunto, a favor de Diego Pacheco de la Puebla de 28.000 maravedises, principal de un censo de 2.000, por cuanto habían sido entregados por éste a su sobrina Gracia, mujer que fué de Feliciano de Silva. Año 1564». (Hernández Vegas, 1982: 106-107)

La citada Gracia, ya viuda de Feliciano, mantuvo pleito con los herederos del arcediano, el anteriormente citado Hernando de Silva. Según Narciso Alonso Cortés,

Al morir en 1564 don Juan Gómez de Silva, arcediano de Sabugal, comprador de las casas, había dejado el usufructo de ellas a su hijo don Hernán Gómez de Silva, también arcediano de Sabugal y canónigo de Ciudad Rodrigo, y la posesión del mayorazgo y vínculo a su sobrino Antonio de Silva. Murió éste sin hijos, y le sucedió en el derecho, como ya hemos visto, su hermano don Hernando de Silva, el cual a su vez trasmitióle a su hijo don Diego de Silva, nacido de su matrimonio con doña María de Cárdenas. (Alonso Cortés, 1933: 46)

Obsérvese algo importante y que nos pone sobre la pista de «dos personajes» de la Segunda Celestina: los aludidos Juan Gómez de Silva, arcediano de Sabugal, y su hijo "Hernán Gómez de Silva, también arcediano de Sabugal y canónigo de Ciudad Rodrigo». En la obra de Feliciano de Silva, Celestina se esconde en casa del "arcediano viejo» y del "arcediano». ¿Existe tras de estas alusiones una referencia, aunque oculta, a sus familiares el "arcediano viejo» Juan Gómez de Silva y su hijo, el también «arcediano» 
Hernán Gómez de Silva con el que contendió su esposa Gracia Fe años después de haber fallecido Feliciano de Silva? Parece muy probable.

\section{3.- Algunas claves de la biografía de Feliciano de Silva para la interpretación de la Segunda Celestina}

Al final de la obra, Félides explica a Sigeril, Polandria y Poncia la verdad sobre la pretendida —en realidad falsa— «resurrección» de Celestina con estas palabras:

Y esta es la verdad; que lo de Júpiter y Venus todo
es burla, como ellos son dioses de burlas. Y sea en
gran secreto, porque el arcediano viejo me lo dijo,
que con esto le quiso pagar muchas deudas de cuan-
do era mozo, que de esta buena mujer había rece-
bido [...] iY sea muy secreto, porque correría gran
peligro la buena dueña con la justicia si se supiese! (Sil-
va 2016: 347-348)

Parece que Feliciano de Silva está refiriéndose a algunas circunstancias reales de su familiar el arcediano Juan Gómez de Silva, con el que tuvo diversos negocios y también desencuentros como ya he expresado en el apartado anterior. Este individuo debía de tener un carácter bastante fuerte, pues llegó a ser desterrado de Ciudad Rodrigo por orden de un corregidor de la localidad, según Luis Fernández en su trabajo sobre «Feliciano de Silva y el movimiento comunero en Ciudad Rodrigo» (1977), al que califica de «belicoso».

Murió, como señala Narciso Alonso Cortés, en 1564, diez años más tarde que Feliciano, el cual falleció con setenta y cinco de edad. Y, como ya he señalado, tuvo un hijo de nombre Hernán Gómez de Silva que también fue, como su padre, arcediano de Sabugal, en Portugal, y asimismo, como este, canónigo en Ciudad Rodrigo. En la obra, aunque la referencia es a un solo personaje, parece que el inconsciente le falló a Feliciano a la hora de escribir la comedia y así, en un momento lo llama «arcediano» y en otro «arcediano el viejo». ¿Está inspirándose en ambos, padre e hijo, los familiares arcedianos del autor de la Segunda Celestina que le incomodaron a él y, más tarde, a su esposa, Gracia Fe? Probablemente.

Según Salazar y Castro (1585: 196 del tomo II), Juan Gómez de Silva fue hijo de Juan de Silva el viejo y de doña Teresa del Águila, primo carnal por tanto de Feliciano. Y, por lo que parece, alcanzó una importante fortuna haciéndose cargo de negocios en Ciudad Rodrigo y en Portugal. Según Mateo Hernández Vegas en su historia de Ciudad Rodrigo y su catedral, en 1534 - el mismo año de la publicación de la Segunda Celestina-don Juan Gómez de Silva, arcediano de Sabugal, cedió a la catedral el «riquí- 
simo beneficio de La Fregeneda que producía 200.000 maravedíes con lo que criaban niños expósitos». Era, asimismo, propietario de alcabalas del vino, carne y diversas heredades de Ciudad Rodrigo. Según Mateo Hernández Vegas, tuvo otro hijo, de nombre «Francisco de Guzmán, coronel, cronista de Felipe II, hijo de don Juan Gómez de Silva, arcediano y canónigo, y compuso el libro Triunfos de Guzmán» (Hernández Vegas, 1982: 122).

Celestina se dirige a Zenara en la cena siete en estos términos:

No tengas, mi amor, celos de mí, que ni la edad del señor Arcediano el viejo requiere, ni la mía lo demanda; y si lo has por pensar que me ha de dar algún interesse, sabe, mi amor, que no calçan sino a quien rompen. Assí que he querido dezirte lo dicho para que no bivas comigo engañada, porque ya es tiempo de salir a fingir mi resurrección, y no quiero, señora, que quedes con sospecha $y$, por parte de tenella, con quexa de la que no se deve de mí tener. Que, como crees en Dios, puedes tener por fe que ni yo tengo tales. (Silva, 1988: 171)

Y Zenara - la barragana del arcediano- recrimina a Celestina lo que entonces era vox populi, su relación, cuando era joven, con el viejo arcediano de la ciudad:
ZENARA.- Señora, yo me corro, por cierto, de lo que has pensado, mas huelgo de lo que dizes para que sepas, como amiga, que no he dexado de tener alguna sospecha de ti; y esto no te maraville, porque me han dicho que quando moça tuviste ciertas pendencias con el Arcedia- no, y ya sabes que a los años mil torna el río por donde solía yr. Mas yo quedo satisfecha de ti, y cree que por mí no serás descubierta. (Silva, 1988: 172)

A lo que Celestina contesta no negando, sino ratificando con rotundidad las palabras de Zenara:

CELESTINA.- He, he, he. Bien sé que en tanto que huviere lenguas que no faltarán falsos testimonios; ¿y por quál carga de agua, mi amor, si yo fuera primera con el Arcediano, havía de ser tercera para contigo, para perder lo servido al tiempo de la paga? Perdóneselo Dios y perdónetelo, que como Dios es verdad, para contigo como mi madre me parece estoy, y no te dexo yo de confesarte que no quedara por el Arcediano, si, quando éramos moços, yo consintiera en su desseo; mas cree, señora, que pues yo te di a ti la mano, que le di a él del pie. jAy bova, ay bova!, ¿y por tan nescia tienes tú a Celestina, 
que si algo desso huviera, que renunciara en ti el beneficio sin que le quedara regresso? No creas, mi amor, que si tan caro me costaran las burlas del Arcedianazgo, que tan barato renunciara el derecho de sus beneficios. (Silva, 1988: 173)

En otro momento, cuando alude a los negocios del arcediano, señala Celestina que:

CELESTINA.- ¡Ay, mi amor, y cómo estás tan engañada! $¡ \mathrm{O}$, quién pudiesse, comadre, dezirte quánto el señor Arcediano procuró comprar caro lo que tú tan barato de mi honrra querías comprar! (Silva, 1988: 175)

La biografía de Feliciano de Silva está también presente en el personaje protagonista de la obra, Félides. A nadie se le puede escapar, pese a que la crítica no ha reparado en este importante dato de carácter onomástico, que Félides es el anagrama o forma abreviada de Feliciano de Silva. En su forma pastoril, Félides toma el nombre bucólico de Filínides, que no es otra cosa, asimismo, que la sublimación onomástica y literaria del último nombre, Félides: otra vez Feliciano de Silva. De manera que en la obra del autor de la Segunda Celestina el elemento autobiográfico es fundamental y está presente a lo largo de toda la obra como podemos detectar también en la onomástica de los personajes.

En realidad, esto no es ninguna novedad. Ya antes Jacopo Sannazaro ocultó, o encubrió, su propio nombre en el personaje de Sincero en su Arcadia. Y años más tarde, el buen amigo de Silva, el portugués Jorge de Montemayor, hará lo mismo emulando al escritor italiano cuando aparezca oculto bajo la onomástica de Sireno, en los Siete libros de la Diana, nombre muy semejante al Sincero de Sannazaro. Como he señalado en otro estudio (Cáseda, 2019), Montemayor llamó a su protagonista Diana encubriendo su auténtico nombre, doña Ana Muñiz, natural y vecina de la localidad leonesa de Valencia de D. Juan.

Montemayor, al comienzo de su novela, dice algo relevante que, sin embargo, no indica Feliciano de Silva en su obra:

"Y de aquí comienza el primero libro. Y en los demás hallarán muy diversas historias de casos que verdaderamente han sucedido, aunque van disfrazados debajo de nombres y estilo pastoril». (Montemayor, 1981: 1)

Jorge de Montemayor fue un buen amigo de Feliciano de Silva, al que dedicó, con ocasión de su muerte, el conocido «Epitafio a la sepultura de Feliciano de Silva» que dice así: 


\begin{abstract}
¿Quién yaze aquí? Un docto caballero.
¿De qué linage? Silva es su apellido.

¿Qué poseyó? Más honra que dinero.

¿Cómo murió? Así como ha vivido.

¿Qué obras hizo? El vulgo es pregonero.

¿Murió muy viejo? Nunca moço ha sido;

pero, según su ingenio sobrehumano,

por tarde que muriese, fue temprano.
\end{abstract}

(Montemayor, 1932: 446).

Escribió también una "Elegía a la muerte de Feliciano de Silva» (Hubbard, 1971).

Por otra parte, los nombres de algunos personajes de su Diana ocultan, en realidad, los de varios amigos poetas. Es el caso de Felicia o de Felis y Felismena, en relación evidente con el nombre de su buen amigo Feliciano de Silva. Para Cravens, la influencia de Silva sobre Montemayor es algo muy perceptible. Para este investigador, «Silva fue el eslabón más importante entre los libros de caballerías, cancioneros y teatro pastoril, de principios del siglo XVI y La Diana de Montemayor» (Cravens, 1976: 112).

Según Manuel Cerezo Magán (2005), el juego con la onomástica de los amigos poetas se extiende a lo largo de varias composiciones. Con el nombre, por ejemplo, de Floresindos, encubre Reinoso en su égloga «Baltea» a su amigo Feliciano de Silva. Y a este, a su vez, lo situamos bajo el nombre de Felisendos en obras de Feliciano de Silva, o de Florisendos en la Égloga V de Bernardim de Ribeiro. Núñez de Reinoso lleva a su novela bizantina titulada Los amores de Clareo y Florisea a un personaje llamado Felisendos de Trapisonda, el cual hace, una vez más, referencia a su amigo Feliciano de Silva.

¿Hace algo parecido este último en la Segunda Celestina años antes? ¿Existe una clara presencia de la biografía vital y literaria de Silva en la Segunda Celestina además de lo ya señalado?

La obra es una "comedia» con final feliz, a diferencia de la "tragicomedia» acabada por Rojas y por Alonso de Proaza. Y cada una de sus partes, como las obras portuguesas o la Hipólita, se divide no en actos sino en cenas, forma abreviada de escenas. No deja, sin embargo, de ser sorprendente que en la obra aparezca un personaje de nombre Zenara - la amiga del arcediano- de cierta relevancia, que tal vez aluda, onomásticamente, a la familia del señor de las islas Canarias, Diego de Aracena, contemporáneo de Feliciano de Silva. Un recuerdo a aquellas islas que él pudo conocer en su viaje a América lo encontramos en el personaje de Canarín, uno de los primeros que alude, al menos onomásticamente, en nuestra literatura, a aquellas islas. Pero también podríamos ver en la referencia insistente a cena o Aracena a lo largo del texto una alusión, aunque encubierta, al apellido de su esposa, Gracia Fe de Caracena, hija del judeocon- 
verso que marchó a Portugal Hernán de Caracena, quien, a lo que parece, dejó a su hija recién nacida al cuidado de Catalina Maldonado, esposa de Juan Pacheco Osorio, quinto señor de Cerralbo.

Sabemos que los Cerralbo mantuvieron una relación importante con Ciudad Rodrigo, pues el sucesor del anterior, su nieto Rodrigo Pacheco Osorio de Toledo, VI señor de Cerralbo y I marqués de Cerralbo, mandó construir en 1533 la casa de los Cerralbo en la plaza mayor de la localidad, edificio que actualmente se conserva en muy buen estado.

$Y$ tenemos noticia, por lo que señala el propio Feliciano de Silva, de que su familia se opuso a su boda, alrededor de 1520, con Gracia Fe por dos razones: sus orígenes judíos, como se ha dicho insistentemente; pero también por la importante diferencia de edad. Si el autor de la Segunda Celestina había nacido en 1479, contaba con al menos cuarenta y un años cuando se casó con Gracia. Y esta debía de ser mucho más joven, probablemente nacida en 1492, año de la partida a Portugal de su padre. Dejamos de tener notica de esta última a partir de los años ochenta, treinta años después del fallecimiento de Feliciano (1554), cuando tal vez murió.

No deja de ser curiosa la relación de cercanía onomástica entre Catalina Maldonado y Celestina, facilitadora o intermediaria de los amores entre Félides y Polandria. ¿Es el personaje de Celestina un trasunto de la esposa del V señor de Cerralbo, Juan Pacheco Osorio, doña Catalina Maldonado, cuya onomástica es tan parecida a la de aquella? Hemos de suponer que $\mathrm{D}^{\mathrm{a}}$ Catalina no vio con malos ojos que su amadrinada, que recogió de brazos de su padre, el judío Hernán de Caracena, y en cuya casa fue bautizada a la fe católica — quizás de ahí su propio nombre (Gracia Fe)— se desposara con un miembro de una de las familias más relevantes y prominentes de la localidad. ¿Fue $\mathrm{D}^{\mathrm{a}}$ Catalina, como Celestina en la novela, quien facilitó aquella relación? Es muy probable que así sea.

Hay un problema, sin embargo, a nivel onomástico, en cuanto a la identificación de Polandria con Gracia Fe. El significado de esta palabra ("poliandria»), en su primera acepción, tal y como la recoge el Diccionario de la Real Academia de la Lengua Española es: 'Estado de la mujer casada simultáneamente con dos o más hombres'. Y tal significado no encaja de forma lógica con la esposa de Feliciano de Silva, madre de sus siete hijos y mujer que elogió en su Amadís de Grecia.

Sin embargo, la segunda acepción de la voz "poliandria» es 'condición de la flor que tiene muchos estambres' (DRAE). El estambre es el órgano reproductor de la flor. Quizás con el nombre de Polandria Feliciano de Silva hace referencia a su esposa y madre de los siete hijos que con ella tuvo.

La onomástica de la literatura de la época de Feliciano de Silva ha sido apenas estudiada por María Coduras Bruna, autora de una Tesis Doctoral titulada La antroponimia en los libros de caballerías españoles: el ciclo amadisiano (2013) y también del trabajo Por el nombre se conoce al hombre: 
Estudios de antroponimia caballeresca (2015). $\mathrm{M}^{\mathrm{a}}$ Carmen Pina ha investigado este asunto (1990: 165-175). Géal, en relación a la novela pastoril, lo ha trabajado en su "Contribución a una semiología de los personajes. Algunas consideraciones onomásticas acerca de Los siete libros de la Diana de Jorge de Montemayor» (2005). A este podemos añadir el más antiguo, y también menos exhaustivo, de Iventosch (1975: 114-123).

El primer género literario que ideó una onomástica muy sugerente en cuanto a significatividad fue el de las caballerías. Pero también, luego, y siguiendo su modelo, el sentimental y el pastoril. Una referencia no muy estudiada en estos ámbitos es el del mundo vegetal, tan presente en estas obras: véase el nombre de personajes como Rosicler, Florestán, Floriano, Laureanos, etc. Quizás el más exitoso de todos los escritores, en cuanto a novela amorosa, fue Diego de San Pedro con su Cárcel de amor. En esta última, se desarrollan los amores de Leriano y Laureola que acaban con el suicidio del primero a causa de los desprecios de aquella. La crítica no ha reparado en que el nombre de esta última es el de una planta muy bella, pero, a su vez, muy venenosa. Su nombre científico es Daphe laureola y uno de los nombres comunes con que es conocida, antes y ahora, es hoja de San Pedro ${ }^{18}$. Ambos nombres tienen una evidente relación con la Cárcel de amor y con el apellido de su autor.

La bella ninfa Dafne fue requerida por Apolo, enamorado de ella pese a sus desprecios (Grimal, 2009: 76). Apolo la persiguió una y otra vez y, cuando por fin iba a ser alcanzada, se convirtió en un laurel. Apolo, así, nunca pudo tenerla. Como tampoco Leriano - Apolo- pudo tener a su Dafne -Laureola-.

Sin duda, el autor de la Cárcel de amor sabía que la laureola era, en su nombre más común y popular, la hoja de San Pedro. Nombre que guarda relación con su apellido. Y, por otra parte, conocedor de su carácter tóxico, dio tal nombre a la amada de Leriano, la cual provoca su muerte a causa de su desprecio. Las cartas de Laureola, quemadas y convertidas en ceniza que toma Leriano mezcladas con agua son, en realidad, tan tóxicas como la propia amada y la planta que puede provocar la muerte de un ser humano, la laureola, también llamada Daphne laureola. Bajo mi punto de vista, es bastante evidente la onomástica de la amada de Leriano.

En el mismo sentido, el nombre de Polandria alude a la esposa de Feliciano de Silva, Gracia Fe, madre de su familia numerosa, y más en concreto a los estambres de la flor, expresión de su capacidad reproductora.

Pero existe una curiosa correspondencia entre las diversas parejas de enamorados de la obra, algo habitual en la literatura de la época. Las relaciones entre Sigeril y Poncia, entre Pandulfo y Quincia, etcétera no tienen mucho de particular. Exceptuando al primero, el resto alude a relaciones

18.- Recuperado de: <http://www.infojardin.net/fichas/plantas-medicinales/daphne-mezereum.htm>. Consultado 04/05/2020. 
entre prostitutas y criados o rufianes. Pero existe una versión pastoril, arcádica e idealizada de los amores de dos personajes completamente ajenos al resto. Me refiero al de los pastores Acays y Filínides.

En un momento de la comedia, Polandria decide escuchar el canto lastimoso de Filínides a causa de la actitud desdeñosa de su amada Acays. Se trata de un momento pastoril y sublime de la obra que recuerda a la Arcadia de Sannazaro. Por un extraño proceso, Félides-onomásticamente Feliciano de Silva - se convierte en Filinides, también trasunto del autor de la obra. Pero también Polandria, esto es la 'flor portadora de muchos estambres', pasa a transformarse onomásticamente en Acays, esto es la casia o la 'adelfilla, Dapne laureola, o torvisco', una bella clase de flor que nos lleva, nuevamente, a la flor que da nombre a la amada de Leriano en la Cárcel de amor de Diego de San Pedro. Todas ellas son flores - la casia o la laureloa y el torvisco- con alguna conocida representación literaria y poética, por ejemplo en el poema que Fernando de Herrera dedica a Garcilaso de la Vega donde dice:

Arda la rota aljaba y pasadores,
La mirra y casia, y quanto el encubierto
Fenix quema; y con verso grave y cierto
Cante su gloria Febo y tus dolores.
Lasso, por quien el Tajo al rico Tebro [...]

(Herrera, 1808: 196)

Como ya he señalado, fue algo muy habitual entre los amigos y contemporáneos de Feliciano de Silva la alusión onomástica entre sí en sus composiciones literarias. Feliciano aparece en obras de sus amigos como Felisendo o Florisendo, etc. ¿Ocurre algo parecido en la Segunda Celestina? Muy probablemente. Por ejemplo, tras Montondoro o Montón Doro en la comedia es probable que podamos adivinar al poeta Rodríguez Montero, buen amigo de Feliciano de Silva y de Jorge de Montemayor, a los que dedicó algunas composiciones poéticas.

Es probable que tras el personaje de Dueñas podamos ver el trasunto de otro amigo poeta -Juan de Dueñas- contemporáneo de Montemayor, de Castillejo, de Boscán, de Garcilaso, de Mendoza, de Cetina, etc.

En cualquiera de los casos, se trata de un juego de alusiones, guiños literarios de reconocimiento poético y de amistad.

En otras ocasiones, Feliciano de Silva se limita a llevar a su comedia a buena parte de los personajes del texto original, aunque no renuncia a algunas modificaciones o adaptaciones literarias, insertando, por ejemplo, el personaje de Tripa en Brazo como compinche de Traso el Cojo. Rosa Navarro se refiere a

[...] una auténtica invasión del mundo de La Celestina en el terreno literario de la nueva comedia, donde se mez- 
clan los «viejos» personajes con los recién aparecidos, y así los lectores saben que pisan terreno conocido, que están en un mismo espacio literario y que el tiempo es algo posterior al de la obra de Rojas. (Navarro, 2018: 376)

Rosa Navarro ha subrayado una gran novedad en la obra: la pareja de criados formada por Sigeril y Poncia, prefiguración de los criados de la comedia nueva del XviI:

Una feliz disidencia de Feliciano de Silva con respecto a su fuente es la de introducir una segunda pareja que sirve de complemento a la principal: la que forman Sigeril, el paje de Felides, y Poncia, la inteligente criada de Polandria; como es bien sabido, será el esquema esencial de la comedia nueva, que en Himenea de Torres Naharro se había esbozado ya, pero sin la hondura que le da el novelista; y en La comedia Thebaida podría haberse planteado, pero el paje Aminthas es un joven que seduce a unas y a otras, aunque escriba al final de la obra una canción amorosa a Claudia, la criada de Cantaflua. Sigeril, hijo del ama de Felides, "sabio y fiel criado» - como dice su amo-, es el intermediario entre el mundo prostibulario, que maneja el mozo de espuelas, Pandulfo, y el cortesano de los señores. Silva, en vez de inclinarlo al goce de las prostitutas, como hace Fernando de Rojas con Pármeno, lo mantiene fiel a su amo y lo enamora de Poncia, la discreta e inteligente criada de Polandria. Desde la escena XIV, tras la resurrección de Celestina, se dibuja ya la doble pareja: la de los señores y la de los criados en la conversación que mantienen la dama y su doncella (Silva 2016: 104). Y culminará en la última escena, con el encuentro de las dos parejas. (Navarro, 2018: 382)

A nivel onomástico, Sigeril alude al 'sigilo' o 'silencio' y, a diferencia de los personajes de la primitiva Celestina, se caracteriza por su discreción. Y Poncia, cuya onomástica latina es evidente, alcanza una gran dignidad y se convierte en modelo de inteligencia natural, a diferencia de la prostituta Quincia.

Evidente resulta, a este respecto, la onomástica del personaje de Fraudador, cuyo nombre deja pocas dudas sobre su modo de actuar. Este y otros aúnan una doble condición, según vieron primero Menéndez Pelayo y luego Emilio José Sales Dasí. Según este último:

Silva experimenta con las posibilidades comicas del amor, que además de una sandez es también una gracio- 
sa locura en las páginas de la Segunda parte del Florisel. (Sales Dasí, 2005:139)

Este investigador señala que tanto Cervantes como Feliciano de Silva reinterpretan «algunos tópicos relativos a la descripción del caballero». Aunque reconoce que ambos resuelven por cauces distintos tal asunto, sin embargo los dos tienen una igual concepción perspectivista de los códigos amorosos. Por ello, indica que

La falibilidad del mundo caballeresco y de sus héroes y la opción elegida de convertir determinados gestos o personajes en argumentos risibles revela un distanciamiento del autor con respecto a sus propias ficciones. Este distanciamiento intencionado, irónico si se quiere, hace palpable la conciencia que Silva y el mismo Cervantes tienen de tales relatos como ficción pura $y$, por tanto, modelable más allá de las exigencias de la realidad empírica. A partir de esta perspectiva se puede interpretar, por ejemplo, la utilización que hace Fraudador de otros motivos típicos de los libros de caballerías para urdir sus engaños y, consiguientemente, plantear otras situaciones cómicas. (Sales Dasí, 2005:139)

Tal vez por ello Menéndez Pelayo insistió en que la Segunda Celestina es «la única de sus obras que merece sobrevivirle, aunque no sea una obra maestra. Tal como es, sería grande injusticia medirla con la misma vara censoria que al D. Florisel de Niquea o al D. Rogel de Grecia" (Menéndez Pelayo, 1961: 68).

Menéndez Pelayo, como Sales Dasí, reconoce que la parte cómica de la obra es muy importante aunque "la parte de la germanía y del hampa [...] son de una prolijidad espantable y de un verismo tosco y brutal». Ciertamente, la obra se puebla, especialmente a partir de la mitad de la misma, de personajes como Pandulfo, muy cercano al Galteiro de la Thebayda. Dignos compañeros de este, según el crítico cántabro, son, en bellaquerías y truhanadas

los dos pajes de Felides; Corniel, el mozo de espuelas; Barañón, el mozo de caballos; el rufián Crito, amante de Elicia; su rival Barradas, el despensero Grajales, Albacín el paje del infante (don Fernando de Austria, hermano de Carlos V), mancebo de rubios cabellos y poquísima vergüenza; y descendiendo todavía más, el tabernero Montón de oro, los rufianes Tripa en brazo, y Traso el cojo, el viejo primo de Celestina Barbantesco, y la inmunda ramera Palana, daifa de Pandulfo. Toda esta canalla está tomada visiblemente del natural: no 
son tipos convencionales como el de Pandulfo. Tienen en sus hechos y dichos una animación endiablada. (Menéndez Pelayo, 196: 76)

Aunque Menéndez Pelayo apuesta porque tal vez la acción de la comedia de Silva puede situarse en Salamanca a partir de las alusiones a la "Horca del Teso", sin embargo hay varias referencias al mar dentro de la obra que indican que su autor tuvo en cuenta la referencia última de la obra original concluida por Rojas y Proaza a las naves de Pleberio que veía desde lo alto de su torre en el famoso planto que concluye la obra.

Se ha dicho, a este respecto, que Feliciano apenas salió de Ciudad Rodrigo a lo largo de toda su vida, afirmación problemática por cuanto sabemos que estudió en Salamanca, que viajó a América y que mantuvo, según Carmen Marín Pina (1991: 118), un "espíritu inquieto y aventurero «.

La obra de Silva se caracteriza, en definitiva por lo que se ha dado en llamar «hibridismo» o, según Martín Lalanda (2002), «entrelazamiento temático", en que se mezclan los elementos novelesco, teatral y poético $y$, en cualquier caso, lo caballeresco, lo rufianesco y lo pastoril. A este respecto, como ya he señalado, Filínides y Acays son claros antecedentes de los personajes de la pastoral del XVI que llega hasta Cervantes y Lope de Vega, herederos a su vez del Darinel del Amadís de Gaula. Y Feliciano de Silva se convirtió así, sin saberlo, en el mejor ejemplo de unión de los géneros literarios de su época, como años después hará Cervantes en muchas de sus obras, especialmente en el Quijote.

\section{Conclusiones}

Una vez acabado este estudio, creo que podemos establecer las siguientes conclusiones:

1. A fecha de hoy, la biografía de Feliciano de Silva tiene todavía muchas partes oscuras que ni la crítica ni los estudios han completado ni tampoco valorado. Este trabajo da cuenta de los pocos que se han ocupado previamente de este asunto (apenas Luis Fernández y María Carmen Marín Pina) y de su Segunda parte de la Celestina.

2. Tras realizar un recorrido por lo poco que conocemos de la biografía de Feliciano de Silva, aporto un buen número de documentos que he localizado en el Archivo Histórico de la Nobleza, relacionados tanto con su vida como con la de sus padres, con la de sus hermanos, de su esposa e hijos y de otros familiares.

3. Creo que puedo, por fin, dar noticia concluyente de su fecha de nacimiento, 1479, puesto que si acepta en 1504 una serie de cesiones y donaciones de sus familiares, así como el patrimonio de 
su padre Tristán de Silva, es porque ese mismo año alcanza la mayoría de edad - 25 años-, condición dispuesta previamente en el testamento de este último para hacerse cargo del mismo, una vez fallecido su hermano mayor.

4. Establezco la relación familiar de Feliciano con los duques de Béjar, a cuyo titular dedica su Segunda parte de la Celestina. A un descendiente dedicará años más tarde Cervantes su Quijote, quien, como es bien sabido, no dejó muy bien parado al autor del Lisuarte de Grecia.

5. Doy cuenta de las dificultades económicas que le persiguieron a lo largo de toda su vida y, tras su muerte, a su esposa. Tiene por ello razón Jorge de Montemayor cuando, en su elegía con ocasión de su fallecimiento, habla de "fama más que dineros». Y establezco sus principales acreedores: sus primos y, entre ellos, el «arcediano el viejo» -Juan Gómez de Silva-y el hijo del anterior, el también «arcediano» Hernán Gómez de Silva. Ambos aparecen en la obra como dos personajes —en realidad es el mismo, que esconde en su casa a Celestina-: el "arcediano el viejo» y el "arcediano».

6. Llevo a cabo un análisis del origen de la onomástica en la obra. El nombre de la antigua amante del arcediano - Zenara- alude al nombre de su esposa, Gracia Fe de Caracena, hija del judío Hernán de Caracena. El nombre de Félides, Filínides en su versión pastoril, no deja de ser un juego onomástico con su propio nombre: Feliciano de Silva.

7. Propongo que Celestina encubre, en su forma biográfica, a quien cuidó desde niña a su esposa y medió en su matrimonio, doña Catalina de Maldonado, quien vio con buenos ojos y favoreció la boda de su amadrinada con Feliciano de Silva.

8. Aludo al curioso juego onomástico con los nombres de plantas y flores en la obra, algo habitual en la novela caballeresca y luego en la pastoril y sentimental. De este modo, Polandria no alude a quien está 'casada varias veces', sino a la condición de la planta con muchos estambres; esto es, a su esposa y madre de siete hijos.

9. Pongo en relación la obra de Feliciano de Silva con las de su círculo de amistades literarias, especialmente los judeoconversos portugueses Jorge de Montemayor, Sá de Miranda, Bernardim de Ribeiro y el castellano Núñez de Reinoso. Y encuentro que hay diversas referencias en la obra a otros escritores por medio de personajes como Dueñas - tal vez el poeta Juan de Dueñas-, Montón Doro —quizás Rodríguez Montero- etc. Analizo el origen de otros como Sigeril, Quincia, Poncia, etc.

10. Finalmente, considero que la obra forma parte de lo que se ha llamado «hibridismo literario» o "entrelazamiento temático»: unión 
o conjunción en la arquitectura literaria de una misma comedia o novela de diversos géneros y estilos, de influencias metaliterarias diversas, subgéneros, etc. anticipándose cronológicamente a lo que hará en el siguiente siglo Miguel de Cervantes en el Quijote con indudable éxito.

\section{Bibliografía}

Alonso Cortés, Narciso (1933), "Feliciano de Silva», Boletín de la Real Academia Española, XX, pp. 382-404.

Arrabal, Fernando (1987), "Feliciano de Silva (Autor Maldito)», Genios y figuras, Madrid, Espasa-Calpe, pp. 103-117.

Asensio, Eugenio (1972), "Alonso Núñez de Reinoso Gitano Peregrino y su égloga Baltea", Studia Hispanica in honorem R. Lapesa, Madrid, Gredos, pp.119-136.

BARANDA, Consolación (1984), "Algunas notas sobre la presencia de la Tragicomedia de Rojas en la Segunda Celestina», Dicenda, 3, pp. 207-216.

- (1987), "Novedad y tradición en los orígenes de la prosa pastoril española», Dicenda, 6, pp. 359-371.

- (1988), "Introducción» a su ed. Segunda Celestina, Madrid, Cátedra, pp. 25-102.

BARANDA, Nieves (2003), "Las lecturas femeninas», en Historia de la edición y la lectura en España 1472-1914, dirigida por Víctor Infantes, Francois López y Jean Fraçois Botrel, Madrid, Fundación Germán Sánchez Ruipérez, pp. 161-167.

BuCETA, Emilio (1931), "Algunas noticias referentes a la familia de Feliciano de Silva», Revista de Filología Española, 18, pp. 390-392.

CÁsEDA, Jesús (2019), "Pruebas documentales sobre la identidad de la Diana de Jorge de Montemayor: Doña Ana Muñiz en los archivos de Valladolid», Estudios Humanísticos. Filología, 41, pp. 153-169.

Cerezo, Manuel (2005), "El mito clásico en la novela pastoril: Jorge de Montemayor y Gaspar Gil Polo», Faventia, 27/2, pp. 101-119.

Coduras, Bruna (2013), La antroponimia en los libros de caballerías españoles: el ciclo amadisiano, Zaragoza, Prensas de la Universidad de Zaragoza.

- (2015), Por el nombre se conoce al hombre: Estudios de antroponimia caballeresca, Zaragoza, Prensas Universitarias de Zaragoza.

Cotarelo y Mori, Emilio (1926), «Nuevas noticias biográficas de Feliciano de Silva», Boletín de la Real Academia Española, 13, pp.129-139.

Cravens, Sydney P. (1976), Feliciano de Silva y los antecedentes de la novela pastoril en sus libros de caballerias, Chapell Hill, Estudios de Hispanófila.

EISEnberg Daniel y Ma Carmen Marín Pina (2000), Bibliografía de los libros de caballerías castellanos, Zaragoza, Prensas Universitarias de Zaragoza. 
FERNÁNDEZ, Luis (1977), "Feliciano de Silva y el movimiento comunero en Ciudad Rodrigo", Archivos Leoneses: Revista de estudios y documentación de los Reinos Hispano-Occidentales, 62, pp. 285-358.

GaGliardi, Donatella (2007), «La Celestina en el Índice: argumentos de una censura», Celestinesca, 31, pp. 59-84.

García Fernández, Máximo (2016), "Tutela y minoría de edad en la Castilla rural: prácticas cotidianas de Antiguo Régimen», Studia Histórica, 38 , pp. 27-54.

GéAL, François (2005), "Contribución a una semiología de los personajes. Algunas consideraciones onomásticas acerca de Los siete libros de la Diana de Montemayor». En Christophe couderc, y Benoit PellistranDI, (eds.), Por discreto y por amigo. Mélanges offerts à Jean Canavaggio, Madrid, Casa de Velázquez, pp. 411-430.

Gómez, Gaspar (2016), Tercera parte de la tragicomedia de Celestina, en Segundas Celestinas, ed. de Rosa Navarro Durán, Madrid, Biblioteca Castro.

Gonzalo Sánchez-Molero, José Luis (2018), «Las obras de Feliciano de Silva en los inventarios de las bibliotecas hispánicas del Siglo de Oro: lectura y presencia», Celestinesca, 42, pp. 339-374.

Grimal, Pierre (2009), Diccionario de mitología griega y romana, Madrid, Paidós.

Hernández Vegas, Mateo (1982), Ciudad Rodrigo: la catedral y la ciudad, Salamanca, Gráficas Cervantes.

Herrera, Fernando (1808), Rimas de Fernando de Herrera, edic. Ramón Fernández, Madrid, Imprenta Real.

Heugas, Pierre (1973), La Célestine et sa descendance directe, Bordeaux, Éditions Bière, Bibliothèque de l'École des Hautes Études Hispaniques.

Hubbard Rose, Constance (1971), Alonso Núnez de Reinoso: The lament of a Sixteenth-Century Exile, Rutherford, Farleigh Dickinson University Press.

Iventosch, Herman (1975, Los nombres bucólicos en Sannazaro y la pastoral española. Ensayo sobre el sentido de la bucólica en el Renacimiento, Madrid, Castalia.

Lida de Malkiel, María Rosa (1962), La originalidad artística de la 'Celestina', Buenos Aires, Eudeba.

MARín Pina, Ma Carmen (1990), «El personaje y la retórica del nombre propio en los libros de caballerías españoles», Tropelías, 1, pp. 165-175.

- (1991), «Nuevos datos sobre Francisco Vázquez y Feliciano de Silva, autores de libros de caballerías», Journal Hispanic Philology, 15, pp. 117-130.

Markova, Alla (2009), "Un fragmento manuscrito de una novela de caballerías en judeo-español», Sefarad, vol. 69:1, pp. 159-172.

Martín Lalanda, Javier (2002), "El ciclo de Florisel de Niquea (1532-15351551) de Feliciano de Silva", Edad de Oro, 21, pp. 153-176.

Menéndez Pelayo, Marcelino (1961), Orígenes de la novela, $2^{a}$ ed., Madrid, Consejo Superior de Investigaciones Científicas. 
Montemayor, Jorge de ([1559] 1981), Los siete libros de la Diana, Madrid, Editora Nacional.

- (1932) (ed.), Cancionero, Madrid, Sociedad de Bibliófilos Españoles.

Montero García, Gema (2016), Edición y estudio del libro segundo de 'La crónica de los muy valientes yesforçados e invencibles cavalleros don Florisel de Niquea'. Memoria para optar al grado de doctor, Madrid, Universidad Complutense de Madrid. Recuperado de: <https://eprints.ucm. es/39940/1/T37938.pdf>. Consultado el 03/05/2020.

Navarro Durán, Rosa (2015), "¿Murió o no murió Celestina? El texto literario como desmentido", en Porque eres, a la par, uno y diverso. Homenaje al profesor Antonio Sánchez Trigueros, Antonio Chicharro (ed.), Granada, Universidad de Granada, pp. 563-580.

Rallo, Asunción (1995), "Introducción» a su ed. La Diana, de Jorge de Montemayor, Madrid, Cátedra, pp. 11-96.

Salazar y Castro, Luis (1685), Historia genealógica de la casa de Silva, Madrid, Melchor Álvarez y Mateo de Llanos.

Sales Dasí, Emilio José (2001) «Feliciano de Silva, aventajado «continuador» de Amadises y Celestinas", en La Celestina, V centenario (1499-1999): Actas de Congreso Internacional Salamanca, Talavera de la Reina, Toledo, La Puebla de Montalbán, 27 de septiembre - 1 de octubre de 1999, coord. Felipe B. Pedraza Jiménez, Gemma Gómez Rubio y Rafael González Cañal, Cuenca, Universidad de Castilla-La Mancha, pp. 403-414.

- (2005), «El humor en la narrativa de Feliciano de Silva: en el camino hacia Cervantes", Literatura: teoría, historia, crítica, 7, pp. 115-157.

Silva, Feliciano de (1988), Segunda Celestina, ed. de Consolación Baranda, Madrid, Cátedra.

- (2016), Segunda comedia de Celestina, en Segundas Celestinas, ed. de Rosa Navarro Durán, Madrid, Biblioteca Castro.

Snow, Joseph T. (2018), "El mundo celestinesco que vivió Feliciano de Silva y que nutrió su Segunda Celestina (1534)», Celestinesca, 42, pp. 323-338.

Teijeiro Fuentes, Miguel Ángel (1988), La novela bizantina española. Apuntes para una revisión del género, Cáceres, Universidad de Extremadura.

Teijeiro Fuentes, Miguel Ángel y Javier Guijarro Ceballos (2007), De los caballeros andantes a los peregrinos enamorados: la novela española en el Siglo de Oro, Cáceres, Eneida.

Valverde, José María, y Manuel Criado de Val (1976), Las Celestinas, Barcelona, Planeta.

WHINNOM, Keith (1988), "El género celestinesco: origen y desarrollo», en García de la Concha, Víctor (coord.), Literatura en la época del Emperador, Salamanca, Academia Literaria Renacentista, pp. 119-130. 